\title{
Humanistyka wobec rozwoju technologii cyfrowych
}

Ewa Szczęsna

TEKSTY DRUGIE 2017, NR 1, S. 301-313

DOI: 10.18318/td.2017.1.25

umanistyka jest jedna, choć wielodziedzinowa i w toku rozwoju cywilizacji - zmieniająca się. Jest dynamiczną jednością, której niezmienność lokuje się w byciu przestrzenią autonomicznego myślenia, zaś zmienność - w sferze metod myślenia i przedmiotów interpretacji. Humanistyka zajmuje się rozumieniem tekstu (także wówczas, gdy deklaruje inne cele). Ten główny przedmiot humanistyki, jej zadanie polegające na kształtowaniu umiejętności myślenia, interpretowania tekstu, niezależnie od tego, czy jest to tekst literatury, innych sztuk (plastycznych, widowiskowych, audiowizualnych, muzyki); czy też tekst innych dyskursów (filozofii, dziennikarstwa, socjologii, polityki, ekonomii, fizyki, matematyki i wielu innych), czyni ją, w jej istotowym wymiarze, koniecznym narzędziem każdej dziedziny - podstawowym egzystencjałem. Humanistyka jako taka wyznacza nasz ludzki sposób istnienia, odróżnia od innych bytów nie-ludzkich, sytuuje wobec nich (i innego człowieka) w postawie dialogu. Jest koniecznym narzędziem i warunkiem wynalazczości i odkrywania w każdej dziedzinie ludzkiej działalności. Mówić
Ewa Szczęsna - dr

hab. prof. nadzw.

UW; specjalizuje się w zakresie poetyki, semiotyki i perswazji wieloznakowych, multimedialnych i interaktywnych tekstów kultury współczesnej; autorka książek: Poetyka reklamy; Poetyka mediów. Polisemiotyczność, digitalizacja, reklama.

Kontakt: e.szczesna@uw.edu.pl 
o humanistyce jako nieprzydatnej dla gospodarki i technologii, pozbawionej techniczno-innowacyjnego potencjału, skazanej na marginalizację, to nie rozumieć jej istoty. Działać na rzecz takiej marginalizacji, to hamować rozwój dziedzin, w których imieniu to działanie się podejmuje - to po prostu im szkodzić.

Jednocześnie humanistyka jest zmienna - w sposób konieczny - ponieważ zmienne są przedmioty jej badań - teksty, które znajdują się w stanie nieustannej ewolucji; ponieważ zmienne są estetyki, idee i ideologie, które je inspirują; ponieważ zmienne są technologie ich produkcji i dystrybucji czy wreszcie stan wiedzy w określonych dziedzinach, a także ponieważ zmienna jest rzeczywistość społeczno-historyczna. Zmiana czynników kontekstowych współtworzących tekst w efekcie ich wzajemnych interakcji powoduje zmiany w sferze rozumienia tekstu. Wymaga tworzenia nowych narzędzi jego opisu i modyfikacji narzędzi dotychczasowych, wydobywania z przedmiotów interpretacji teorii i metodologii, tworzenia kolejnych perspektyw poznawczych i reinterpretacji tych zastanych. Zmiany te to sfera niestałości czy też nieustannej ewolucji humanistyki, która jest określana jako nowa wówczas, gdy pojawiają się kolejne przemodelowania w jej sferze. Przy czym, rzecz charakterystyczna, zmienność humanistyki nieustannie wzmacnia przestrzeń niezmienności. Oto bowiem dynamika zmian, różnorodność w sferze badania zjawisk tekstowych, rozwoju dyskursu polemicznego, kreowania nowych perspektyw widzenia rzeczy, odmiennych sposobów fokalizowania, poznawania stabilizuje i potwierdza niezmienność interpretacji jako istoty humanistyki.

Troska o rozumienie tekstu jest też podstawowym zajęciem interesującej się sztuką słowa (choć nie tylko) humanistyki polonistycznej i to zarówno wtedy, gdy zajmuje się konkretnymi utworami, jak i wtedy, gdy spiera się o teorie, metodologie - sposoby czytania tekstu (gdy zajmuje się filtrami i narzędziami poznawczymi) czy wreszcie zastanawia się nad istotą interpretacji i próbuje ją określić. Przykładową ilustracją tego niezmiennego wiązania istoty humanistyki z interpretacją (choć różnie rozumianą) są dwie oddalone od siebie upływem 40 lat wypowiedzi: Marii Janion oraz Michała Pawła Markowskiego.

Szkołą myślenia humanistycznego jest interpretacja, czyli rozumienie ludzkich wytworów i zachowań. Interpretacja jest sztuką artystów i uczonych, ale jest również podstawową umiejętnością myślącego człowieka. Bez tej umiejętności zamknięty zostaje przed nim świat kultury i świat nauki. Ponawia się zatem stale konieczność nauczenia r o z u m i e n i a 
i wy b o r u, czyli humanistycznej interpretacji dzieł człowieka i wyboru wartości uznawanych za najwyższe. ${ }^{1}$

Jeśli powiadam, że [humanistyka] powinna być przestrzenią kształcenia wrażliwości, to powiadam także, że jest ona dyscypliną interpretacji. [...] Humanistyka to taka gimnastyka umysłu, która uczy nas lub wzmacnia przekonanie, że ludzie różnie sobie świat z dostępnych znaczeń komponują, aczkolwiek robią to w tej samej przestrzeni, w której i my się trudzimy. ${ }^{2}$

Zajmując się zatem niezmiennie interpretacją, humanistyka polonistyczna przejawia tendencję do modelowania jej rozumienia (kształtowania nowych teorii, metodologii) oraz poszerzania pola badań - rozluźniania definicji tekstu ${ }^{3}$. To ostatnie prowadzi do wyjścia poza tekst określonej formy dyskursywnej (literatury) i medialnej (druku) w stronę innych dyskursów (np. tekstów sztuki, tekstów społecznych, dziennikarskich, naukowych) i mediów (audiowizualnych, interaktywnych).

Humanistyka polonistyczna czy może lepiej tekstologiczna jest zatem nowa za każdym razem, gdy zmienia filtr interpretacyjny lub/oraz (gdyż często oba te warunki się łączą), gdy zaczyna interesować się nowymi formami tekstów. Obecnie np. chętnie sięga po perspektywę poznawczą nauk przyrodniczych, medycznych, którymi bada zjawiska tekstowe. Z kolei nowym przedmiotem badań czyni przekaz cyfrowy.

Technologia cyfrowa znacząco modyfikuje materię znaku i jego strukturę. Nowa organizacja znaku tekstowego (mającego swoją reprezentację na poziomie programowania i użytkowania, rozproszonego, niematerialnego, łączącego funkcję znaczenia i działania - mediacyjną i operacyjną) wyznacza nową ontyczność nadbudowanego nad znakiem tekstu. Z kolei nowy sposób istnienia tekstu wymusza zmiany w sferze jego opisu. Pojawia się konieczność modyfikacji zastanych narzędzi badawczych, wytwarzania narzędzi nowych, wreszcie wydobycia $\mathrm{z}$ badania tekstu teorii zdolnych nazwać nowe

1 M. Janion Wizje nowej humanistyki, w tejże: Humanistyka: poznanie i terapia, PIW, Warszawa 1982, s. 109-110. Cytowany fragment pochodzi z artykułu powstałego w 1970 roku.

2 M.P. Markowski Wrażliwość, interpretacja, literatura, "Teksty Drugie” 2010 nr 1/2, s. 112, 113, 122.

3 Np. mówienie o tekście jako o: strategii, która ustanawia uniwersum własnych interpretacji (Umberto Eco), tym, co daje się przeczytać (Markowski), węźle sieci relacji, które wnikają w środowisko społeczne, historyczne i kulturowe, przekształcając je (Ryszard Nycz). 
zjawiska tekstowe i dyskursywne. W efekcie technologia cyfrowa zmienia humanistykę.

Teza ta dotyczy zresztą nie tylko technologii cyfrowej, ale także szeroko pojętej techniki, która - jak pisał Martin Heidegger - „[...] nie jest samym tylko środkiem, [ale] [...] sposobem odkrywania"4. "Jej istota nie jest niczym technicznym. Techne „należy do wy-dobywania [...] jest czymś poietycznym"s. Dobrego przykładu dostarczają technologie pisma i druku, które uwolniły formę tekstową od realizowania funkcji mnemonicznej - poszukiwania i stosowania struktur tekstowych ułatwiających zapamiętywanie. Zamiast tego forma tekstowa mogła w znacznie większym stopniu realizować funkcję estetyczną - rozwój sztuki literackiej gwarantowały nie podejmowane tematy, ale zabiegi formalne, oryginalne rozwiązania w sferze formy artystycznej. Możliwe stało się np. coraz dalej idące komplikowanie form narracji, kształtowanie poezji konkretnej, ale także przekształcanie poezji w stronę form nieregularnych, eksperymentalnych, literackiego użycia interpunkcji, przedstawień graficznych (np. książka ilustrowana). Podobnie było z fotografią, która uwolniła malarstwo od realizowania zapotrzebowania na odwzorowanie i ułatwiła rozwój sztuki abstrakcyjnej.

Panujący dość powszechnie pogląd przeciwstawiający technikę humanistyce, głoszący dewaluację humanistyki czy jej wypieranie przez osiągnięcia techniki, przeciwstawianie humanistyki technologii jest zatem przesądem. Technologie i media uczestniczą w kreowaniu tekstów artystycznych, kształtowaniu humanistyki równie dobrze, jak przemiany społeczne, polityczne, ekonomiczne - krótko mówiąc, wszelkie zmiany kulturowe ${ }^{6}$. Stanowią jedną ze stałych zmiennych w sieci relacji czynników tworzących tekst. Sprawiają, że każdy tekst jest konstruktem społecznym i kulturowym, zakotwiczonym w określonych porządkach dyskursywnych, medialnych, semiotycznych, odpowiedzialnych za jego spójnossćn.

4 M. Heidegger Technika izwrot, przeł. J. Mizera, Wydawnictwo Baran i Suszczyński, Kraków 2002, S. 16.

5 Tamże.

6 Tezę o wpływie medium na tekst i jego znaczenie a także o literaturze jako doświadczeniu zapośredniczanym medialnie i przez medium modelowanym formułują i uzasadniają Peter Gendolla oraz Jorgen Schäfer. Zob. P. Gendolla, J. Schäfer Playing With Signs. Towards an Aesthetic Theory of Net Literature, w: The Aesthetics of Net Literature. Writing, Reading and Playing in Programmable Media, ed. by P. Gendolla, J. Schäfer, Transcript, Bielefeld 2007, s. 17-36.

7 Zob. T. Van Leeuwen Introducing Social Semiotics, Routledge, New York 2005, s. 181-267. 
Technologie cyfrowe dysponują narzędziami semiotycznego uspójniania tekstów, uzasadniania powiązań między nimi, a także łatwością ich stosowania. Efekt synchronizacji semiotycznej jest uzyskiwany dzięki operowaniu określoną paletą barw na ekranie komputera, wiązaniu elementów tekstowych, ale i zróżnicowanych tematycznie i dyskursywnie tekstów tym samym rytmem (powtarzalnością ruchu, dźwięku, koloru). Dodatkowym czynnikiem uspójniającym są linkowanie i zaprojektowana możliwość manipulowania tekstem, które pozwalają użytkownikowi konstruować tekst zgodnie $\mathrm{z}$ własnym wyobrażeniem tekstu spójnego ${ }^{8}$. W przypadku form fabularnych np. pozwalają na wybór tych elementów tekstowych, które jak oczekuje tego użytkownik, pozwolą mu budować sekwencje zdarzeń i uzyskać całość, której można nadać sens. Jako taki hipertekst nie tyle sam opowiada historie, co stymuluje użytkownika do ich opowiadania.

Zapis cyfrowy jest technologią, która w znacznie większym stopniu niż poprzedzające ją technologie zapisu modyfikuje ontyczność słowa literackiego. Literatura nadal jest sztuką słowa, ale nie tylko semantyki słowa jako znaku umownego. Na rzecz literackości zostają pozyskane inne aspekty słowa - zwłaszcza jego warstwa przedstawień. Słowo zostaje poddane wtórnej, zapośredniczonej medialnie i modelowanej estetycznie ikonizacji, kinetyzacji i udźwiękowieniu. Dobrego przykładu dostarcza reprezentujący poezję cyfrową utwór Roberta Kendalla Faith ${ }^{9}$, w którym wartość semantyczną ma zmieniająca się barwa słów, poszczególnych liter oraz ich ruch - deformacje kształtu, przemieszczenia, pojawianie się i znikanie konotujące zdarzenia i sytuacje ze świata człowieka. Ruszające się, przekształcające na oczach odbiorcy i udźwiękowione litery, wyrazy, fragmenty tekstu alfabetycznego zyskują cielesność. Konotują żywotność. Ruchoma, zmieniająca się tekstura wypiera teksturę nieruchomą, niezmienną - jaka jest charakterystyczna dla tradycyjnej literatury papierowej. Słowo literackie nie jest już przyklejone do kartki, uwięzione na zadrukowanym papierze. Jest słowem rewitalizowanym - biologicznym, często wręcz antropomorfizowanym - może być projektowane jako słowo o cechach ludzkiej osobowości, może opowiadać interakcją kształtu i znaczenia o zachowaniach i relacjach międzyludzkich

8 Zagadnienie zmian w sposobie funkcjonowania spójności hipertekstu w porównaniu ze spójnością analogowego tekstu narracyjnego analizuje Marie-Laure Ryan. Zob. M-L. Ryan Can Coherence Be Saved?, w: tejże Narrative as Virtual Reality. Immersion and Interactivity in Literature and Electronic Media, The Johns Hopkins University Press, Baltimore-London 2001, s. 242-270.

9 Zob. http://collection.eliterature.org/1/works/kendall__faith.html (15.08.2016). 
(jak w Strings ${ }^{10}$ Dana Wabera). Może też zostać uprzestrzennione - zyskiwać trzeci wymiar na ekranie komputera lub być projektowane w przestrzeni odbiorcy - wchodzić z nim w interakcje - jak dzieje się w interaktywnych instalacjach (np. w Screen ${ }^{11}$ Noaha Wardripa-Fruina). Tak istniejące słowo literackie zyskuje cechy sztuk przestrzennych (architektury, rzeźby), wiążąc ze sobą wielowiekowe znaczenia wypracowane w toku rozwoju tych sztuk.

Literatura cyfrowa korzysta też z wypracowanych kulturowo sposobów istnienia słowa, ale - co dla niej charakterystyczne - jednocześnie je przekształca, zderza, remediatyzuje $\mathrm{e}^{12}$. Znaczenie literackie jest kreowane w interakcji zapośredniczonych cyfrowo słowa oralnego, słowa piśmiennego i drukowanego, które poddane kinetyzacji, metamorfozom kształtu i barwy stają się jednocześnie słowami-ikonami. Cyfrowy tekst alfabetyczny w tworzeniu znaczeń wykorzystuje dorobek kultury słowa - kultury oralnej i związku literatury z muzyką (zapośredniczone medialnie mowa, efekty dźwiękowe, muzyka), kultury pisma (czcionki naśladujące pismo ręczne, litery „rysowane" na ekranie, ozdabianie, stylizowanie wyglądu liter) i druku (multiplikacja form czcionek drukowanych wypracowanych w toku rozwoju kultury oraz form grafizacji słowa - rysowania słowem). Uczynienie przedmiotem remediacji wielowiekowego dorobku kultury druku, w szczególności wypracowanych form książki drukowanej, Jay David Bolter uznaje za ważną cechę hipertekstu ${ }^{13}$.

Nadto w tworzeniu znaczeń tekstowych uczestniczą zapośredniczone medialnie, towarzyszące słowu przedstawienia ikoniczne (np. rysunkowe, fotograficzne, malarskie w utworach zamieszczonych na stronie Electronic Literature Collection), muzyczne i audiowizualne pojawiające się na prawach tła, ilustracji; wreszcie interaktywne reprezentujące różne dyskursy - nie tylko dyskurs sztuki (w przywołanym utworze Strings - są to: retoryka, tekstowy wymiar ruchu ciała, dyscyplina sportowa, rebus, elementy gry; w Schemacie ${ }^{14}$

\footnotetext{
Zob. http://collection.eliterature.org/1/works/waber__strings.html (18.08.2016).

Zob. https://www.youtube.com/watch?v=WOwF5KD5BV4 (18.08.2016).

J.D. Bolter, R. Grusin Remediation. Understanding New Media, The MIT Press, Cambridge-London 2000. 2001, s. 45 .

Zob. http://haart.e-kei.pl/hiperteksty/schemat/zl_5.html (20.08.2016).
} 
Konrada Polaka - instrukcja obsługi, w Victory Garden ${ }^{15}$ Stuarta Moulthropa - wykres przedstawiający możliwe porządki czytania).

Prowadzi to do rozwoju humanistyki w zakresie nowych narzędzi badań i nowych szkół myślenia. Obecność w opisie tekstu figur kinetycznych (adiekcji, detrakcji, permutacji, atomizacji), na których opierają się utwory poetyckie (Ars Poetica ${ }^{16}$, cykl Powieki ${ }^{17}$ Zenona Fajfera); narracji alternatywnej (wielowariantywnej); przemodelowania w sposobie istnienia świata przedstawionego, w szczególności „wydobycie go" na powierzchnię tekstury - obecność elementów fabuły na poziomie warstwy przedstawień, kreowanie znaczeń tekstowych w interakcji semantyki słowa jako znaku graficznego i semantyki słowa jako znaku umownego (np. w Blueberries ${ }^{18}$ Susan Gibb, Końcu świata wedtug Emeryka ${ }^{19}$ Radosława Nowakowskiego, Patchwork Girl20 Selley Jackson) to zabiegi tekstowe pracujące na rzecz tworzenia i rozwoju semiopoetyki.

Oderwanie znaku i tekstu literackiego od materialności papieru zostaje zastąpione powiązaniem go z programowalnością i interaktywnością. Znak i tekst literacki są przetwarzalne, ich cechą konstytutywną jest modyfikowalność - zarówno na poziomie przedstawień, jak i znaczeń. Ważną rolę zyskuje interfejs, który w utworach literackich nie tylko pełni funkcję pośrednika między użytkownikiem i teksturą, ale sam zostaje utekstowiony (np. polecenie „naciśnij klawisz ESC lub kliknij tutaj, aby doczekać starości” w utworze Młodość 1861 liter później ${ }^{21}$ Leszka Onaka jest jednocześnie narzędziem obsługi tekstu i integralną częścią semantyki tekstu). Podobnie z literackim użyciem komunikatów technicznych mamy do czynienia w hiperpowieści Matrioszka ${ }^{22}$ Marty Dzido, gdzie każdy wybór przez użytkownika linku realizującego myśl

15

Zob. https://www.youtube.com/watch?v=TNo2_RqyXgo (21.08.2016).

Zob. http://www.techsty.art.pl/magazyn3/fajfer/Ars_poetica_polish.html (24.08.2016).

Z. Fajfer Powieki, Wydawnictwo Forma : Fundacja Literatury imienia Henryka Berezy, Szczecin 2013.

Zob. http://www.cddc.vt.edu/journals/newriver/ogFall/gibb/blueberries/titlec.html; w przekładzie Mariusza Pisarskiego: Czarne jagody. Zob. http://haart.e-kei.pl/hiperteksty/czarne_jagody/czarne_jagody.html (24.08.2016).

Zob. http://www.liberatorium.com/emeryk/brzask.htm (24.08.2016).

Zob. https://www.youtube.com/watch?v=KXFEqyXrbqU (24.08.2016).

Zob. http://techsty.art.pl/m10/mlodosc_1861_liter_pozniej/(26.08.2016).

Zob. http://haart.e-kei.pl/matrioszka/start.html (28.08.2016). 
samobójczą bohaterki skutkuje ukazaniem się planszy z napisem unexpected error (nieoczekiwany błąd systemu). Zupełnie tak, jak gdyby system blokował samobójstwo głównej bohaterki jako to, co oznacza urwanie kluczowego wątku, zatrzymanie fabuły. Do tych przesunięć należy dodać zmiany w sferze relacji komunikacyjnych. I tak, zamiast klasycznego odbioru - mamy do czynienia z doświadczaniem tekstu w akcie tworzenia, ze sprawczym działaniem użytkownika, cielesnym, sensorycznym i mentalnym jego uczestnictwem w ustanawianiu utworu.

Istotne zmiany zachodzą też w sferze autorstwa - by wspomnieć tu chociażby twórczość kolaboratywną (transautorstwo) czy odbiorczą partycypację w działaniach na teksturze (czego efektem jest narracja kombinowana percepcyjno-partycypacyjna). Zatem podczas gdy w tradycyjnej literaturze życie utworu gwarantowały przede wszystkim uniwersalność podejmowanego tematu, artyzm i oryginalność tekstu, a nade wszystko jego otwartość interpretacyjna, w dobie kultury cyfrowej dodatkowym czynnikiem jest możliwość tworzenia jego nowych odsłon, modyfikowania, rozwijania tekstury we współpracy wielu osób - użytkowników i jednocześnie współtwórców. Czynnikiem gwarantującym trwanie tekstu jest jego ontyczna niegotowość.

Wyzwaniem dla współczesnego literaturoznawstwa jest niewątpliwie rozmach, z jakim tworzone są utwory transsemiotyczne, transmedialne, transdyskursywne deklarujące literacki charakter. Co więcej, interakcja różnych semiosfer, mediów, dyskursów w obrębie jednego utworu (transmedialność i transdyskursywność wewnątrztekstowa) znajduje też odpowiednik na poziomie ponadjednostkowym tekstem. Interesującym zjawiskiem jest tworzenie form tekstowych, które określam tu roboczo jako makroteksty a które angażują zresztą różne, nie tylko cyfrowe, formy medialne sztuki. Do kategorii tej zaliczam konstrukcje wielotekstowe (obejmujące co najmniej dwa teksty) i wieloautorskie, które wchodzą ze sobą w relacje znaczeniowe, tworząc sensy naddane. Makrotekstami rządzi zasada transtekstowego kreowania znaczeń. Zatem podczas gdy intertekstualność zachowuje dominację tekstu czytanego, w którym obecne sygnały intertekstualne służą modelowaniu znaczeń tekstowych $^{23}$, a przywołania (osyłające do pamięci czytelnika) tworzą kontekst interpretacyjny, w przypadku transtekstualności znaczenie tworzy się w interakcji, wzajemnej ingerencji semantycznej wszystkich tekstów tworzących makrotekst. Poszczególne teksty makrotekstu mogą istnieć osobno i zwykle

23 Przykładem działania intertekstowego w przestrzeni hipertekstu jest nawiązujący do Ogrodu o rozwidlających się ścieżkach Jorge Luisa Borgesa utwór Victory Garden Stuarta Moulthropa. 
tak jest, jednak tworząc makrotekst, wchodzą w swoisty dialog, którego efektem jest znaczenie naddane. Ów dialog wynika z tego, że sygnały transtekstowe przebiegają w obu kierunkach, są zwrotne, nie zaś jednokierunkowe, jak w przypadku klasycznej intertekstualności. Przykładem takiego makrotekstu może być relacja, w jaką wchodzi instalacja Text Rain Camille Utterback i Romy Achituv z kaligramem Il pleut Apollinaire'a oraz wierszem Evana Zimrotha Talk, You, który został użyty w instalacji. Wiersz Apollinaire'a - deszcz malowany literami słów mówiących o padaniu; instalacja interaktywna, w której widoczne na ekranie, padające słowa wiersza mogą zostać zatrzymane tylko przez ciało odbiorcy; wiersz Zimrotha, w którym spojrzenia, gesty, cielesność, łączą dwoje ludzi bardziej i prawdziwiej niż dystansujące słowa, wchodząc ze sobą w interakcje, stają się opowieścią o różnych obliczach słowa i ciała, o ich zdolności i bezsilności komunikowania, oddawania znaczeń. Roberto Simanowski podkreśla, że jak w wierszu Zimrocha, rozmowa okazuje się bezcelową, pustą konwersacją, tak w Text Rain bezcelowy, pusty semantycznie jest cielesny kontakt użytkownika ze słowami ${ }^{24}$.

Wyraźne ślady (i formy obecności) różnych mediów i dyskursów, współkształtujące znaczenia tekstów cyfrowych, sprawiają, że nasuwa się pytanie o to, czy wciąż jeszcze mamy tu do czynienia z literaturą (pytanie o literackość tych utworów). W moim przekonaniu o literaturze w środowisku cyfrowym można mówić wszędzie tam, gdzie funkcję dominującą, organizującą, inicjalną w kreowaniu utworu pełni semantyka słowa jako ruchomego znaku arbitralno-ikonicznego modelowanego artystycznie. Od literatury papierowej cyfrowa różniłaby się przede wszystkim mnogością form warstwy przedstawień i jej kinetyczną ontycznością oraz wzmocnieniem roli kinetycznej i udźwiękowionej tekstury w kształtowaniu znaczeń literackich. Źródłem impulsu znaczeniotwórczego są interakcje, w jakie wchodzą semantyka warstwy przedstawień i świat kreowany z semantyką słowa drukowanego jako znaku arbitralnego. W interakcji obu poziomów kształtowane są figury literackie - zwłaszcza metafory, metonimie, paralelizmy, ironia, ale także kształtowana jest narracja (doskonałym przykładem może być wspomniana już powieść hipertekstowa Susan Gibb). Rezultatem digitalizacji tekstury

24 R. Simanowski Digital Art and Meaning. Reading Kinetic Poetry, Text Machines, Mapping Art, and Interactive Installations, University of Minnesota Press, Minneapolis-London 2011, s. 3 8. Zob. też: F.J. Ricardo Reading the Discursive Spaces of Text Rain, w: Literary Art in Digital Performance. Case Studies in New Media Art and Criticism, ed. by F.J. Ricardo, Continuum, New York-London, s. 61-63. 
literackiej jest też obecność wspomnianych wyżej figur kinetycznych organizujących chociażby poezję cyfrową Zenona Fajfera czy Łukasza Podgórniego.

Kolejną istotną cechą jest projektowanie formy przestawienia, która zakłada ukazywanie się utworu na wiele różnych sposobów - tworzenie w efekcie linkowania fabuł wyznaczanych przez potencjalne porządki narracyjne. Rezultatem jest kształtowanie fabuł wielowariantywnych, w których mamy do czynienia z narracją alternatywną i partycypacyjną ${ }^{25}$, czyli taką, która już na poziomie percepcyjnym ma wiele równoprawnych porządków przebiegu i w której o wyborze określonego porządku decyduje odbiorca.

W rezultacie wielość możliwych interpretacji utworu literackiego (charakteryzująca sztukę literacką także przed pojawieniem się kultury cyfrowej) zostaje zwielokrotniona wielością możliwych form jego ukazywania się. Zastąpienie tekstury utrwalonej, niezmiennej, teksturą dziejącą się na oczach odbiorcy, której elementy słowne przekształcają się, ujawniają lub zanikają na ekranie lub w przestrzeni i są zależne od działań użytkownika, oznacza, że cyfrowy tekst literacki już w warstwie przedstawień jest procesem i działaniem, że zyskuje wymiar sprawczy i performatywny. Ten ostatni aspekt ujawnia się zwłaszcza w przypadku elektronicznych hologramów, instalacji ${ }^{26}$, gdzie utwór słowno-ikoniczny na prawach spektaklu mediatyzuje i tekstualizuje przestrzeń rzeczywistą.

Badanie literatury cyfrowej, rozumianej jako taka forma artystyczna, która nie mogłaby być zrealizowana poza medium digitalnym, wymaga kompetencji tekstologicznych i szeroko pojętych kompetencji humanistycznych oznaczających wyjście poza tradycyjne literaturoznawstwo. Wymaga tego, co Simanowski nazywa hermeneutyką digitalną ${ }^{27}$ a co sprowadza się do kreowania kategorii, narzędzi opisu w swobodnej interakcji teorii tekstu literackiego, sztuk plastycznych, dźwiękowych, audiowizualnych i programowalnych form przekazu. Wymaga elastyczności myślenia, swobody kojarzenia, ale i śmiałości w kreowaniu narzędzi opisu, wydobywania sygnałów teorii z analiz

(Grahame Weinbren), Text Rain (Camille Utterback, Romy Achituv https://www.youtube.com/ watch?v=toWFvXHghDk), czy w 2008 roku: Typographic Synesthesia (Rachel Stomel, https:// www.youtube.com/watch?v=zg2eOiB5iXo ). Zob. też B. Wands Digital Installation and Virtual Reality, w: tegoż Art of the Digital Age, Thames \& Hudson, London 2006, s. 98-121.

27 R. Simanowski What is and Toward What End Do We Read Digital Literature?, w: Literary Art In Digital Performance..., s. 13-15. 
tekstów ${ }^{\mathbf{2 8}}$ cyfrowych i przekuwania ich w teorie w konfrontacji z najnowszymi teoriami różnych dziedzin sztuki, dyskursów, mediów.

Rozwój współczesnej humanistyki inspirowany jest zresztą potrzebą opisu tekstowego i dyskursywnego charakteru nie tylko wytworów cyfrowych technologii, ale również nauk ścisłych, biologicznych, przejawów zachowań społecznych. W istocie jej nowy charakter nie jest fanaberią czy ekskluzywną zachcianką. Jest zarówno potrzebą, jak i normą w kontekście humanistyki tradycyjnej. Jest potrzebą, gdyż zmieniająca się sytuacja tekstowa, dyskursywna, medialna wymaga opisu, refleksji. Gdyż to, co nowe w sferze tekstualności, żąda adekwatnej, sprawczej humanistyki, wymusza jej modernizację. Konsekwencją poszerzania pola badań, pola opisu, konsekwencją zmian w sferze tekstów i dyskursów, które zostają poddane refleksji badawczej, jest reorganizacja immanentna humanistyki.

Dla humanistyki cyfrowej - zarówno technologia, jak i struktura medium nie są transparentne - to czynniki współtworzące tekst, zaangażowane w literackość i jako takie stanowiące przedmiot badań cyfrowego literaturoznawstwa. Humanistyka cyfrowa, w tym również cyfrowe literaturoznawstwo (kreowane w pracach ${ }^{29}$ takich badaczy jak np.: Jay David Bolter, Roberto Simanowski, Jörgen Schäfer, Peter Gendolla, Marie-Laure Ryan, Karin Wenz, Katherine Hayles, Markku Eskelinen, Francisco J. Ricardo; u nas zaś np.:

28 Konieczność dążenia do "wygenerowania rodzimych propozycji teoretycznych wychodzących z analiz własnego materiału badawczego" i nie tylko własnego głosi Ewa Domańska, zob. tejże Jakiej teorii potrzebuje współczesna humanistyka, „Teksty Drugie” 2010 nr 1/2, s. 54.

Zob. np. Reading Moving Letters. Digital Literature in Research and Teaching, ed. by R. Simanowski, J. Schäfer, P. Gendolla, Transcript, New Brunswick-London 2010; Beyond the Screen. Transformations of Literary Structures, Interfaces and Genres, ed. by J. Schäfer, P.Gendolla, Transcript, New Brunswick-London 2010; C.T. Funkhouser New Directions in Digital Poetry, Continuum, New York-London 2012; The Aesthetics of Net Literature. Writing, Reading and Playing in Programmable Media, ed. by P. Gendolla, J. Schäfer, Transcript, New Brunswick-London 2007; J.D. Bolter Przestrzeń pisma. Komputery, hipertekst i remediacja druku, przeł. A. Małecka, M. Tabaczyński, Ha!art - Bydgoszcz: Miejskie Centrum Kultury, Kraków-Bydgoszcz 2014; M. Pisarski Xanadu. Hipertekstowe przemiany prozy, Ha!art, Kraków 2013; U. Pawlicka (Polska) poezja cybernetyczna. Konteksty i charakterystyka, Ha!art, Kraków 2012; Hiperteksty literackie. Literatura i nowe media, red. M. Pisarski, P. Marecki, Ha!art, Kraków 2011; „Teksty Drugie” 2014 nr 3 oraz 2015 nr 3 (numery poświęcone cyfrowości); Przekaz digitalny. Z zagadnień semiotyki, semantyki i komunikacji cyfrowej, red. E. Szczęsna, Universitas, Kraków 2015; Liberatura, e-literatura i... Remiksy, remediacje, redefinicje, red. M. Górska-Olesińska, Wydawnictwo UO, Opole 2012; P. Kubiński Gry wideo. Zarys poetyki, Universitas, Kraków 2016; M. Maryl Życie literackie w sieci. Pisarze, instytucje i odbiorcy wobec przemian technologicznych, Wydawnictwo IBL PAN, Warszawa 2015. 
Mariusz Pisarski, Urszula Pawlicka, Piotr Marecki, Monika Górska-Olesińska, Ewa Wójtowicz, Maciej Maryl, Agnieszka Przybyszewska, Emilia Branny), poszerzające i modyfikujące pole refleksji humanistycznej, jest naturalnym następstwem procesów społecznych, ekonomicznych, cywilizacyjnych. Jest koniecznością wobec rozwoju form tekstowych i dyskursywnych, które domagają się opisu i interpretacji.

Rozrastająca się przestrzeń cyfrowa z nową budową i nowymi funkcjami znaku tekstowego, nową formułą tekstu i dyskursu, reinterpretująca sposób istnienia tekstu sztuki, kategorii autorstwa, odbioru, gatunku tekstowego, figuratywności, narracji jest dla humanistyki (zwłaszcza młodej) tym, czym np. dla ekonomii był wynalazek pieniądza, a dla turystyki wynalazek koła. Jest wielką szansą na jej rozwój, na wyjście poza teorie końca, śmierci i kolejne posty w stronę tworzenia nowych form tekstowych i dyskursywnych oraz ich badania, nazywania i problematyzowania. Jest zaproszeniem do interpretowania cyfrowych form ekspresji artystycznej, ale także zmian dokonujących się pod ich wpływem w sferze gatunków zastanych. 


\section{Abstract}

\section{Ewa Szczęsna}

UNIVERSITY OF WARSAW

The Humanities and the Development of Digital Technologies

This article puts literary digital forms and scholarly discussions on them on the map of the development of the humanities. The digital humanities are shown to attend to the formation of tools that are appropriate to the study of the artistic texts, which is changing in terms of semiotics, discourse and communication. Szczęsna points out the unique traits of the literary hypertext - textual interventions that initiate the construction and development of semiopoetics. These are, in particular, the creation of kinetic figures (adjection, detraction, permutation, atomization), alternative narrations; the construction of a plot on the level of representation; the creation of textual meanings in the interaction of the semantics of the word as a graphic-sonoric sign and as an arbitrary sign. One interesting effect of the digitalization of texts and discourses is the creation of macrotexts - multi-textual and multi-authored constructions which, by interacting, give rise to additional meanings.

\section{Keywords}

semiotics, poetics, semiopoetics, digital literature, digital humanities, rhetorical figures 